DOI: $10.4274 /$ tod. 94830

\title{
Çağın Pandemisi: D Vitamini Eksikliği ve Yetersizliği
}

\author{
Pandemic Era: Vitamin D Deficiency and Insufficiency
}

Fatma Fidan, Berat Meryem Alkan, Aliye Tosun

Ankara Atatürk Eğitim ve Araştırma Hastanesi, Fiziksel Tıp ve Rehabilitasyon Kliniği, Ankara, Türkiye

\section{Özet}

D vitamini; yağda eriyen vitaminler arasında yer almakta olup aynı zamanda endojen olarak uygun biyolojik ortamda sentezlenebildikleri için hormon ve hormon öncüleri olan bir grup steroldür. En önemli etkisi kalsiyum, fosfor metabolizması ve kemik mineralizasyonu üzerinedir. Son yıllarda, D vitamini eksikliği ve yetersizliğinin, yaygın kanserler, kardiyovasküler hastalıklar, metabolik sendrom, enfeksiyöz ve otoimmun hastalıkların dahil olduğu bir çok kronik hastalıklarla ilişki içinde olduğu bulunmuştur. Aynı zamanda D vitamini eksikliği osteoporoz, düşme ve kırıklar için tanımlanmış bir risk faktörüdür. D vitamini eksikliği artık küresel bir salgın olarak kabul edilmektedir. 25(OH)D düzeyi 20 ng/ mL'den düşük ise D vitamini eksikliği, 21 ile $29 \mathrm{ng} / \mathrm{mL}$ arasında ise $D$ vitamini yetersizliği, $30 \mathrm{ng} / \mathrm{mL}$ 'den yüksek ise yeterli düzey (tercih edilen aralık 40-60 ng/mL) ve $150 \mathrm{ng} / \mathrm{mL}$ 'den yüksek ise D vitamini intoksikasyonu olarak kabul edilmektedir. D vitamini eksikliği çocuklarda rikets, erişkinlerde ise osteomalazi klinik tablosuna neden olmaktadır. Bu derlemede; günümüzde çok yaygın olan yetişkinlerdeki $D$ vitamini yetersizliği ve eksikliğinin tanımlanması ve tedavi yönetimine güncel bir yaklaşım sunmayı amaçladık. (Türk Osteoporoz Dergisi 2014;20: 71-4)

Anahtar kelimeler: D vitamini, 25(OH)D vitamini, osteomalazi

\section{Summary}

Vitamin D is not only a fat-soluble vitamin, but also a group of hormone and hormone precursor sterols that can be synthesized endogenously in appropriate biological conditions. Its most profound effect is on calcium and phosphorus metabolism, and on bone mineralization. In recent years, it was reported that Vitamin D deficiency and insufficiency are related with many chronic diseases such as widespread cancers, cardiovascular diseases, metabolic syndromes, infectious diseases and autoimmune diseases. Vitamin D deficiency is also a defined risk factor for osteoporosis, falls and fractures. Vitamin D deficiency is now recognized as a global epidemic. $25(\mathrm{OH})$ Vitamin D levels under $20 \mathrm{ng} / \mathrm{mL}$ is accepted as Vitamin D deficiency, levels between $21-29 \mathrm{ng} / \mathrm{mL}$ as insufficiency, over $30 \mathrm{ng} / \mathrm{mL}$ as sufficient levels (preferred range is between 40-60 ng/mL), and over $150 \mathrm{ng} / \mathrm{mL}$ as Vitamin D intoxication. Vitamin D deficiency leads to ricketts clinics in children and osteomalacia clinics in adults. In this review, we aimed to define Vitamin D deficiency and insufficiency which is currently widespread in adults, and to provide a current approach to the treatment methods. (Turkish Journal of Osteoporosis 2014;20: 71-4)

Key words: Vitamin D, 25(OH) Vitamin D, osteomalacia

\section{Giriş}

D vitamini; yağda eriyen vitaminler arasında yer almakta olup aynı zamanda endojen olarak uygun biyolojik ortamda sentezlenebildikleri için hormon ve hormon öncüleri olan bir grup steroldür. En önemli etkisi kalsiyum, fosfor metabolizması ve kemik mineralizasyonu üzerinedir $(1,2)$. Bununla birlikte son yıllarda, D vitamini eksikliği ve yetersizliğinin yaygın kanserler, kardiyovasküler hastalıklar, metabolik sendrom, enfeksiyöz ve otoimmun hastalıkların dahil olduğu bir çok kronik hastalıkla ilişki içinde olduğu bulunmuştur $(3,4)$. Bu yaygın hastalıkların spektrumu özellikle endişe vericidir çünkü gözlemsel çalışmalar göstermiştir ki; sanayileşmiş ülkeleri içeren dünyanın kuzey bölgelerinin birçoğunda D vitamini yetersizliği yaygındır (5). D vitamini eksikliği artık küresel bir salgın olarak kabul edilmektedir (6). Ingiltere'de yakın zamanda yapılan bir çalışmada; kış ve bahar dönemlerinde erişkin popülasyonun \%50'sinden fazlasında D vitamini yetersizliği, \%16'sında da ciddi D vitamini eksikliği saptandığı bildirilmiştir (5). Ülkemizden Uçar ve ark. son yıllarda Ankara bölgesinde yaptıkları bir çalışmada; oldukça yüksek oranda $(\% 51,8)$ D vitamini eksikliği ve $\% 20,7$ oranında D vitamini yetersizliği tespit edilmiştir (7).

Yazışma Adresi/Address for Correspondence: Dr. Fatma Fidan, Ankara Atatürk Eğitim ve Araştırma Hastanesi, Fiziksel Tıp ve Rehabilitasyon Kliniği, Ankara, Türkiye GSM: +90 5053507575 E-posta: drfatmafidan@hotmail.com Geliş Tarihi/Received: 06.01.2014 Kabul Tarihi/Accepted: 25.04.2014

Türk Osteoporoz Dergisi, Galenos Yayınevi tarafindan basılmıştır. / Turkish Journal of Osteoporosis, published by Galenos Publishing. 
Yeterli D vitamini alımı ve serumda optimum D vitamini düzeyinin korunması sadece kemik, kalsiyum ve fosfor metabolizması için değil aynı zamanda genel sağlık ve iyilik hali için de çok önemlidir. Global sağlık problemi olarak D vitamini eksikliği ve yetersizliğinin, geniş spektrumlu akut ve kronik hastalıklar için bir risk olması muhtemeldir (8). Bu bilgilerden yola çıkarak bu derlemede; günümüzde çok yaygın olan yetişkinlerdeki D vitamini yetersizliği ve eksikliğinin tanımlanması ve tedavi yönetimine güncel bir yaklaşım sunmayı amaçladık.

\section{Vitamini Kaynakları ve Metabolizması}

Başlıca D vitamini kaynağı; endojen olarak ultraviyole B (UVB) ışınlarının deride fotokimyasal olarak 7 dehidrokolesterolden vitamin D3 (kolekalsiferol) oluşturmasıdır. Güneş ışığına fazla maruz kalınmasıyla vitamin D3 inaktif ürünlerine çevrilmektedir. Diyetle D vitamini, bitkilerde bulunan ergokalsiferol (vitamin D2) ve hayvan dokularında bulunan kolekalsiferol (vitamin D3) şeklinde alınabilmektedir. D vitamini en fazla balık, karaciğer ve yumurta sarısında bulunmaktadır. Diyetle alınan vitamin D2 ve D3 şilomikronlarla birleşerek lenfatik sistem aracılığı ile venöz dolaşıma taşınmaktadır. Diyetle alınan veya endojen olarak yapılan vitamin D2 veya vitamin D3 yağ hücrelerinde depo edilmekte ve gerektiğinde dolaşıma salınmaktadır $(6,9)$.

Deride yapılan veya diyetle alınan $D$ vitamini biyolojik olarak aktif değildir. Önce karaciğerde 25 hidroksilaz enzimi ile 25 hidroksivitamin D'ye [25(OH)D], daha sonra da böbreklerde 1 alfa hidroksilaz enzimi ile biyolojik olarak aktif form olan ve kalsitriol olarak da bilinen 1,25 dihidroksivitamin D'ye [1,25(OH)2D] dönüşmektedir. 1 alfa hidroksilaz enzimi $D$ vitamini sentezinde anahtar enzimdir. Bu enzimin düzenlenmesinde parathormon (PTH), kalsiyum (Ca), fosfor ve fibroblast growth faktör 23 (FGF 23) rol oynamaktadır $(6,9)$. 1,25(OH)2D ince barsak, böbrek ve diğer dokularda bulunan vitamin $D$ reseptörleri üzerinden etkisini gösterir. Ince barsaktan Ca absorbsiyonunu arttırarak, böbreklerden de Ca kaybını azaltarak genel fonksiyonu olan kan kalsiyum düzeyini korur. Ayrıca 1,25(OH)2D vitamininin, hücre proliferasyonu inhibe edici, terminal diferansiasyonu uyarıcı, anjiogenezi inhibe edici, insülin üretimini uyarıcı ve renin üretimini inhibe edici biyolojik etkileri mevcuttur $(9,10)$. D vitamini ve metabolitleri birçok dokuda bulunan 24 hidroksilaz enzim tarafından inaktive edilerek safra yoluyla atılmaktadır $(2,6)$.

\section{Vitamini Düzeyleri}

Kişideki vitamin D düzeyini değerlendirmek için yarı ömrü 2-3 hafta olan, hem vitamin $D$ alımını hem de endojen yapımı gösteren 25(OH)D düzeyine bakılmalıdır. Biyolojik aktif form 1,25(OH)2D ideal ölçüm için uygun değildir. Çünkü yarı ömrü 4-6 saat kadar kısa ve dolaşımdaki düzeyleri 25(OH)D'den 1000 kat daha düşüktür. D vitamini eksikliği ve yetersizliğinin tanımlanması ve 25(OH)D düzeyinin normal aralığının saptanması için birçok çalışma yapılmıştır. Bu çalışmaların ışığında; $25(\mathrm{OH}) \mathrm{D}$ düzeyi $20 \mathrm{ng} / \mathrm{mL}^{\prime}$ den düşük ise $\mathrm{D}$ vitamini eksikliği, 21 ile $29 \mathrm{ng} / \mathrm{mL}$ arasında ise D vitamini yetersizliği, 30 $\mathrm{ng} / \mathrm{mL}^{\prime}$ den yüksek ise yeterli düzey (tercih edilen aralık 40-60 $\mathrm{ng} / \mathrm{mL}$ ) ve $150 \mathrm{ng} / \mathrm{mL}^{\prime}$ den yüksek ise $D$ vitamini intoksikasyonu olarak kabul edilmektedir $(6,10)$.

\section{Kimlerde D Vitamini Düzeyine Bakılmalıdır?}

- Kemik hastalığı olan kişiler (osteomalazi, osteoporoz, paget vs.),

- D vitamini eksikliğini düşündüren kas-iskelet sistemine ait semptomları olan kişiler,

- D vitamini eksikliği ve yetersizliği konusunda risk faktörleri olanlar (koyu tenli kişiler, güneş ışığından yeterince yararlanamayanlar, yaşlılar, obezler, kısa aralıkla sık hamile olanlar, emziren kadınlar, malabsorbsiyon durumları, antikonvülsan ve glikokortikoid ilaç kullanımı vs.).

D Vitamini Yetersizliğinin/Eksikliğinin Klinik, Radyolojik ve Biyokimyasal Bulguları

D vitamini eksikliği çocuklarda rikets, erişkinlerde ise osteomalazi klinik tablosuna neden olmaktadır. Osteomalazide en belirgin yakınma; pelvis, omurga ve kostaları içeren yaygın ağrıdır. Ağrı genellikle belden başlayıp, pelvis, kalça, uyluk, sırt ve kostalara yayllır. Kemik korteksinin incelmesi sonucu tibia, sternum, spinöz çıkıntılar, pelvis ve kostaların derin palpasyonu ile hassasiyet ve ağrı ortaya çıkabilir. Yetişkinlerde görülen osteomalazinin diğer bir klinik bulgusu da antaljik yürüyüş veya yürüme güçlüğüne neden olan proksimal kas güçsüzlüğüdür. Hastalar kollarını kullanmadan sandalyeden kalkmakta, merdiven inip çıkmakta ve yürümekte güçlük çekerler $(11,12)$. Ağır osteomalazide ilk belirti kırık olabilir. Osteomalazinin tipik radyolojik bulgusu yaygın osteopeni ve Looser çizgileri olarak adlandırılan psödofraktürlerdir. Psödofraktürler genellikle uzun kemikler, pubik ve iskiyal ramus, ulna, kosta ve skapulada görülür (11). Osteomalazide biyokimyasal olarak; serum kalsiyum normal veya düşük, serum fosfor düşük, PTH yüksek, ALP yüksek, 25(OH)D düşük, 1,25(OH)2D normal veya yüksek olabilir. Ancak $D$ vitamini eksikliği 1 alfa hidroksilaz eksikliğine bağlı ise $1,25(\mathrm{OH}) 2 \mathrm{D}$ düşük, 25(OH)D ise normal veya yüksek bulunabilmektedir (9).

\section{Osteomalazi Nedenleri}

1. Deride sentezin azalması

- Güneş ışınlarına yetersiz maruziyet

- 70 yaş üzeri kişiler

- Koyu tenli kişiler

2. Biyo yararlanımın azalması

- Malabsorbsiyon (Postgastrektomi, Gluten enteropatisi, Pankreatik yetersizlik, Kistik Fibrozis, Crohn Hastalığı, Bilier Obstrüksiyon vs.)

- Obezite

3. Katabolizmanın arttığı durumlar

- Glikokortikoid ve antikonvülzan ilaç kullanımı

4. $25(\mathrm{OH}) \mathrm{D}$ sentezinin azalması

- Karaciğer yetmezliği

5. 25(OH)D atılımının artması

- Nefrotik sendrom

6. 1,25(OH)2D vitamini sentezinin azalması

- Kronik böbrek yetmezliği

- Hiperfosfatemi

7. Tümör kaynaklı osteomalazi

- Tümörün Fibroblast Growth Faktör 23 salgılaması 


\section{Genetik Hastalıklar}

- Vitamin D Bağımlı Rikets (Tip 1, Tip 2 ve Tip 3)

- Otozomal Dominant Hipofosfatemik Rikets

- X linked Hipoposfatemik Rikets

\section{Vitamini, Osteoporoz, Düşme ve Kırık}

Düşük 25(OH)D vitamin düzeyleri sekonder hiperparatiroidizme yol açarak osteoklastlar üzerinden kemik rezorbsiyonuna neden olduğundan yetişkinlerdeki osteopeni ve osteoporozu hızlandırıp kötüleştirebilirler (13). D vitamini; PTH seviyelerini fizyolojik sağlıklı düzeylerde tutarak osteoblastik aktiviteyi artırıp kemik mineralizasyonunu destekler ve bunun sonucunda da düşme ve kırık oluşma riskini belirgin olarak azaltıllar $(13,14)$. $25(\mathrm{OH})$ D vitamin düzeyi $>30 \mathrm{ng} / \mathrm{mL}$ olan hastalarda kırık riskinin daha düşük olduğuna dair kanıtlar vardır (6). Otuz binden fazla katıımcının olduğu bir meta analiz göstermiştir ki; yaklaşık 800 IU/gün D vitamini ilavesi non-vertebral kırık riskini \%14, kalça kırık riskini ise \%30 azaltarak kırık riskinde önemli bir düşüşe neden olmuştur (15).

25(OH)D vitamini ile alt ekstremite fonksiyonları, proksimal kas gücü ve fiziksel aktivite arasında müspet bir ilişki mevcuttur $(16,17)$. Vitamin D eksikliği özellikle postural denge ve yürüyüş için gerekli olan alt ekstremitenin antigravite kaslarını etkilemektedir (18). Yaşlılarda 25(OH)D vitamini düzeyleri ile düşmeler arasında anlamlı korelasyon bulunmaktadır. Kas gücü, postüral ve dinamik denge $D$ vitamini takviyesi ile artırılabilir $(16,17)$. Gerdhem ve ark. 986 ambulatuvar kadını dahil edip, 3 yıl takip ettikleri çalışmalarında; düşük 25(OH)D vitamin seviyesinin düşük fiziksel aktivite düzeyi, yürüme hızında azalma ve dengede bozulma ile ilişkili olduğunu saptamışlardır. $25(\mathrm{OH})$ $\mathrm{D}<20 \mathrm{ng} / \mathrm{mL}$ olan grupta kırık riskinde artışa yatkınlık olduğunu gözlemlemişlerdir (19).

Sonuç olarak, D vitamini eksikliği osteoporoz, düşme ve kırıklar için tanımlanmış bir risk faktörüdür (20).

\section{Vitamini Eksikliği Önleme ve Tedavi Yaklaşımı}

Normal koşullar altında insan vücudunda bulunan D vitaminin \%90-\%95'i güneş ışınlarının etkisi ile deride sentez edilir. Özellikle içine katılmadıkça besinlerle alınan vitamin D'nin büyük bir önemi yoktur. Güneş ışığı temel kaynaktır ve yeterince faydalanilırsa ilave $D$ vitamini almaya gerek yoktur. Amerika'nın kuzeyinde (Boston, 42 ${ }^{\circ}$ kuzey) haftada 2-3 defa el, yüz ve kolları 5-15 dakika güneşe tutmanın vücudun D vitamini ihtiyacını karşılamak için yeterli olduğunu ortaya koyan çalışmalar mevcuttur $(18,21)$. Bununla birlikte, güneş ışınlarıyla ciltte $D$ vitamini sentezinde mevsimsel ve coğrafik farklııklar olduğunu da unutmamak gerekir. Yaklaşık $33^{\circ}$ enlemin kuzeyinde ve güneyinde yaşayanlarda kış aylarında D vitamini sentezi hemen hemen hiç olmamaktadır (22). Bunun yanı sıra, artmış deri pigmentasyonu, ileri yaş ve topikal güneş kremleri kullanılması gibi birçok faktör derideki bu üretimi azaltmaktadır $(10,21)$. Otuz faktörlü güneş koruma (sun protection factor, SPF) kremlerin ciltte D vitamini üretimini \%95-\%98 oranında azalttığı bilinmektedir. Sekiz SPF güneş kremlerinin bile kandaki D vitamini düzeyini dramatik olarak azalttığı bidirilmiştir (22). Yaşlılarda UV sonrası D vitamini yapma kabiliyetinin 30 yaş altı erişkinlere göre dörtte bir ila beşte bir azalmış olduğunu gösteren kanıtlar mevcuttur. D vitamini kaynağı olarak güneşin kullanılmasını, güneş ışımasını etkileyen bulutlu hava, ozon yoğunluğu, hava kirliliği, rakım, mevsim, günün saati, deri rengindeki farklılıklar ve benzeri diğer faktörler oldukça zorlaştırmaktadır (23).

D vitamini eksikliğini önlemek için Tıp Enstitüsü (Institute of Medicine; IOM); ilk bir yıl infantlara günlük 400 IU D vitamini desteğinin hemen başlanılmasını, 1-70 yaş arasındakilere 600 IU/gün ve 70 yaşın üzerindekilere de $800 \mathrm{IU} /$ gün D vitamini desteğini önermektedir. IOM tarafından önerilen bu dozlar, 25(OH)D düzeyini kemik sağlığı için yeterli olduğu düşünülen $20 \mathrm{ng} / \mathrm{mL}$ seviyelerine çıkarabilir fakat Endokrin Topluluğu'nun önerdiği $30 \mathrm{ng} / \mathrm{mL}$ seviyeleri için yeterli değildir. Bu yüzden D vitamini eksikliğini önlemek için, Endokrin Topluluğu kendi uygulama rehberlerinde; infantlarda ilk bir yıl için günlük 4001000 IU (2000 IU'ye kadar güvenli), 1-18 yaş arasındaki çocuk ve adölesanlar için günlük 600-1000 IU (4000 IU'ye kadar güvenli), 18 yaş üzeri erişkinler için ise günlük 1500-2000 IU (10,000 IU'ye kadar güvenli) D vitamini desteği önermektedir. Bununla birlikte obez kişilerde, Malabsorbsiyon sendromu olan hastalarda, glikokortikoid ve antiepileptik ilaç kullanan kişilerde daha yüksek dozlar gerekebilir (6).

Endokrin Topluluğu, uygulama rehberlerinde yaş ve altta yatan tıbbi durumlara göre D vitamini eksikliği olan hastalar için çeşitli tedavi stratejileri önermişlerdir (10).

- 0-1 yaş arasında D vitamini eksikliği olan bebeklerde; 2000 IU/gün ya da 50,000 IU/hafta vitamin D2 veya D3 altı hafta süreyle, bunu takiben kan 25(OH)D seviyesini $30 \mathrm{ng} / \mathrm{mL}$ 'nin üzerinde tutabilmek için 400-1000 IU/gün idame tedavisi,

- 1-18 yaş arasında D vitamini eksikliği olan çocuklarda; 2000 IU/gün ya da 50,000 IU/hafta vitamin D2 veya D3 altı hafta süreyle, bunu takiben kan 25(OH)D seviyesini $30 \mathrm{ng} / \mathrm{mL}$ 'nin üzerinde tutabilmek için 600-1000 IU/gün idame tedavisi,

- D vitamini eksikliği olan bütün erişkinlerde; $6000 \mathrm{IU} / g u ̈ n$ ya da 50,000 IU/hafta vitamin D2 veya vitamin D3 sekiz hafta süreyle, bunu takiben kan 25(OH)D seviyesini $30 \mathrm{ng} / \mathrm{mL}$ 'nin üzerinde tutabilmek için 1500-2000 IU/gün idame tedavisi,

- Obez hastalarda, malabsorbsiyon sendromu olan hastalarda ve $D$ vitamini metabolizmasını etkileyen ilaç kullanan hastalarda yüksek doz, en azından 6000-10,000 IU/gün D vitamini ile tedavi ve 3000-6000 IU/gün dozda idame tedavisi önerilmektedir.

Ayda iki kez 50,000 IU D vitamini verilme stratejisi altı yıla kadar herhangi bir toksisite olmaksızın D vitamini eksikliği veya yetersizliğini tedavi etmekte ve rekurrensi önlemektedir (6). Son zamanlarda yapılan bir çalışmada; erişkinlerde altı yıl boyunca her iki haftada bir 50,000 IU ya da eşdeğer olarak 3000 IU/gün D vitamini alınması, herhangi bir toksisite olmaksızın kan $25(\mathrm{OH})$ D düzeyini 40-60 ng/mL arasında tutmada etkili bulunmuştur. Çocuk ya da erişkin, D vitamini alımının arttııımasının sarkoidoz ve tüberküloz gibi hastalıkları içeren granulamatoz durumlar hariç bilinen hiçbir zararı yoktur. Bütün erişkinler 2000 IU/ gün D vitamini almalıdır (24). Bununla birlikte, granulamatoz hastalıklar, genetik hastalıklar ya da nadir olarak $D$ vitamini 
metabolizmasını etkileyen enzimlerin polimorfizmi gibi belli durumlarda D vitamini toksisite riski artmıştır (6).

\section{Sonuç}

Ülkemizde ve dünyada D vitamini eksikliği/yetersizliği yaygın olarak görülmektedir. Günümüzde de çeşitli nedenlerle güneş ışınlarından yeterince faydalanılmadığı aşikar olup, bu durumda D vitamininden zenginleştirilmiş yiyecekler veya D vitamini destek tedavisinin önemi artmaktadır.

\section{Kaynaklar}

1. Champe PC, Harvey RA, Ferrier DR. Biyokimya. Ceviri Editörü: Ulukaya E. Lippincott's Illustrated Reviews Serisinden. 3. Baskı. Nobel Tıp Kitapevleri; 2007

2. Bringhurst FR, Demay MB, Krane SM, Kronenberg HM. Bone and Mineral Metabolism in Health and Disease. In: Kasper DL, Braunwald E, Fauci AS, Hauser SL, Longo DL, Jameson JL, editors. Harrison's Principles of Internal Medicine. 16th edition. New York:MCGraw-Hill Companies; 2005. p. 2238-86.

3. Holick MF. Vitamin D: a D-lightful health perspective. Nutr Rev 2008;66:182-94

4. Hyppönen E, Boucher BJ, Berry DJ, Power C. 25-hydroxyvitamin D, IGF-1, and metabolic syndrom at 45 years of age: a cross-sectiona study in the 1958 British Birth Cohort. Diabetes 2008;57:298-305.

5. Pearce SHS, Cheetham TD. Diagnosis and management of vitamin D deficiency. BMJ 2010;340:b5664.

6. Wacker M, Holick MF. Vitamin D-Effects on Skeletal and Extraskeletal Health and the Need for Supplementation. Nutrients 2013;5:111-48.

7. Uçar F, Taşlıpınar MY, Soydaş AÖ, Özcan N. Ankara Etlik İhtisas Eğitim Araştırma Hastanesi'ne Başvuran Hastalarda 25-OH Vitamin D Düzeyleri. Eur J Basic Med Sci 2012;2:12-5.

8. Pludowski P, Holick MF, Pilz S, Wagner CL, Hollis BW, Grant WB, et al. Vitamin $D$ effects on musculoskeletal health, immunity, autoimmunity, cardiovascular disease, cancer, fertility, pregnancy, dementia and mortality- a review of recent evidence. Autoimmun Rev 2013;12:976-89.

9. Öngen B, Kabaroğlu C, Parıldar Z. D Vitamini'nin Biyokimyasal ve Laboratuvar Değerlendirmesi. Türk Klinik Biyokimya Dergisi 2008:6:23-31.
10. Holick MF, Binkley NC, Bischoff-Ferrari HA, Gordon MC, Hanley DA, Heaney RP et al. Evaluation, Treatment, and Prevention of Vitamin D Deficiency: an Endocrine Society Clinical Practice Guideline. J Clin Endocrinol Metab 2011:96:1911-30.

11. Uğurlu H. Osteomalazi, Paget Hastalığı. In: Beyazova M, GökçeKutsal Y, editörler. Fiziksel Tıp ve Rehabilitasyon, Güneş Kitabevi Ankara; 2000. p.1894-902

12. Lane NE. Metabolic Bone Disease. In: Firestein GS, Budd RC, Harris ED, Mclnnes IB, Ruddy S, Sergent JS, editors. Textbook of Rheumatoogy Kelley's, Saunders Elsevier; 2009. p.1579-99.

13. Holick MF. Optimal vitamin D status for the prevention and treatment of osteoporosis. Drugs Aging 2007;24:1017-29.

14. Dawson-Hughes B, Heaney RP, Holick MF, Lips P, Meunier PJ, Vieth R. Estimates of optimal vitamin D status. Osteoporos Int 2005:16:713-6.

15. Bischoff-Ferrari HA, Willett WC, Orav EJ, Lips P, Meunier PJ, Lyons $R A$, et al. A pooled analysis of vitamin $D$ dose requirements for fracture prevention. N Engl J M 2012;367:40-9.

16. Bischoff-Ferrari HA. Relevance of vitamin D in muscle health. Rev Endocr Metab Disord 2012;13:71-7.

17. Bischoff-Ferrari HA, Dietrich T, Orav EJ, Hu FB, Zhang Y, Karlson $E W$, et al. Higher 25-hydroxyvitamin D concentrations are associated with better lower-extremity function in both active and inactive persons aged $\geq 60$ y. Am J Clin Nutr 2004;80:752-8.

18. Akpınar $P$, İçağasıoğlu $A$. The Relation Between Vitamin $D$ and Quality of Life. Türk Osteoporoz Dergisi 2012;18:13-8.

19. Gerdhem P, Ringsberg KA, Obrant KJ, Akesson K. Association between 25-hydroxy vitamin D levels, physical activity, muscle strength and fractures in the prospective population-based OPRA Study of Elderly Women. Osteoporos Int 2005:16:1425-31.

20. Mosekilde L. Vitamin D and the elderly. Clin Endocrinol (Oxf) 2005:62:265-81.

21. Holick MF. Vitamin D and bone health. J Nutr 1996;126:1159-64.

22. Wacker M, Holick MF: Sunlight and Vitamin D: A global perspective for health. Dermato-Endocrinology 2013;5:51-108.

23. Tsiaras WG, Weinstock MA. Commentary: Ultraviolet irradiation and oral ingestion as sources of optimal vitamin D. J Am Acad Dermatol 2010;62:935-6.

24. Holick MF. Vitamin D: extraskeletal health. Rheum Dis Clin North Am 2012:38:141-60. 